\title{
Two Novel Variants and One Previously Reported Variant in the ATP2C1 Gene in Chinese Hailey-Hailey Disease Patients
}

\author{
Zhen Xiao $^{\mathrm{a}}$ Zhi-Gang Liu ${ }^{\mathrm{a}} \quad$ Xiao-Liang Ou Yang ${ }^{\mathrm{a}} \quad$ Si-Min Yu ${ }^{\mathrm{a}} \quad$ Jian-rong Zeng ${ }^{\mathrm{b}}$ \\ Chun-Ming $\mathrm{Li}^{\mathrm{a}}$ \\ aDepartment of Dermatology, The Second Affiliated Hospital of Nanchang University, Nanchang, China; \\ bDepartment of Dermatology, The Third People's Hospital of Fengcheng City, Yichun, China
}

\section{Keywords}

Hailey-Hailey disease · ATP2C1 · Sanger sequencing · Novel mutations

\begin{abstract}
Hailey-Hailey disease (HHD) is a rare autosomal dominant genodermatosis. It is characterized clinically by recurrent erosions, blisters and erythematous plaques at the sites of friction and intertriginous areas. The pathogenic gene of HHD was reported to be the ATPase calcium-transporting type $2 \mathrm{C}$ member 1 gene (ATP2C1). In this study, genomic DNA polymerase chain reaction $(P C R)$ and direct sequencing of ATP2C 1 were performed from 3 Chinese pedigrees and 4 sporadic cases of HHD. We detected 3 heterozygous mutations, including 2 novel mutations (c.1673_1674insGTTG and $c .2225 \mathrm{~A}>\mathrm{G}$ ) and 1 recurrent nonsense mutation (c.1402C>T; NM_014382.4). The ATP2C1 gene was also screened in the asymptomatic members of pedigrees. Our results would further expand the mutation spectrum of the ATP2C1 gene and be helpful in the genetic counseling of patients with HHD.

(c) 2021 S. Karger AG, Basel
\end{abstract}

(c) 2021 S. Karger AG, Basel

www.karger.com $/ \mathrm{ms}$

\section{Introduction}

Hailey-Hailey disease (HHD; OMIM 169600), also known as familial benign chronic pemphigus, is a rare autosomal dominant genetic skin disease [Engin et al., 2015] that was initially described by the Hailey brothers in 1939 [Hailey and Hailey, 1939]. The disease usually develops in the third or fourth decade with an incidence estimated to be 1:50,000-1:40,000 and has no sex predilection [Deng and Xiao, 2017]. Two-thirds of all HHD patients have family histories. Typically, HHD skin lesions consist of recurrent pruritic vesicles, painful erosions, and scaly erythematous plaques, usually involving friction or intertriginous regions such as the neck, axillae, groin, and perineum [Burge, 1992]. Some patients may complain of itching, pain, an unpleasant smell emanating from skin lesions, and have longitudinal white bands in the fingernails [Xiao et al., 2019]. Several trigger factors, such as physical trauma, heat, humidity, secondary infection, stress, and ultraviolet irradiation may exacerbate HHD disease. Painful erosions in the HHD may impact the quality of life greatly. Mucosal involvement is rare, but esophageal involvement has been described [Kono et al., 2019]. In occasional cases, the lesions may develop

\footnotetext{
Karger"
}

Correspondence to:

Chun-Ming Li, chunminglinc@yahoo.com 
into squamous cell carcinomas and basal cell carcinomas [Bitar and Giroux, 1970; Furue al., 1987; Cockayne et al., 2000; Holst et al., 2000]. Additionally, affective disorder has also been described in patients with HHD [Korner et al., 1993].

Histologically, HHD is characterized by extensive epidermal suprabasilar acantholysis, which is known as the "dilapidated brick wall" [Wilgram et al., 1962]. Ultrastructural investigation revealed the diffuse staining of desmosomal protein in the cytoplasm of most acantholytic cells and perinuclear clumping of the filaments [Deng and Xiao, 2017]. In 1994, the pathogenic gene for HHD was first mapped to a $14-\mathrm{cM}$ region on chromosome 3q [Ikeda et al., 1994], which was later narrowed to a 5-cM interval on chromosome 3q21q24 [Richard et al., 1995]. In 2000, the ATP2C1 gene (ATP2C1; OMIM 604384), encoding the human secretory pathway $\mathrm{Ca}^{2+} \mathrm{Mn}^{2+}$-ATPase protein 1 (hSPCA1), was first identified as the pathogenic gene of HHD [Hu et al., 2000]. Diagnosis of HHD is not difficult being based on family history, clinical manifestation, physical examination, histologic examinations, and genetic analyses. In this study, we performed mutation analysis of the ATP2C1 gene in 3 Chinese pedigrees and 4 sporadic cases with HHD, and also performed the molecular diagnosis for the asymptomatic individuals in these HHD pedigrees.

\section{Case Presentation and Methods}

Three Chinese families which included 8 affected members and 17 asymptomatic individuals, 4 sporadic cases, as well as 100 healthy controls were included in this study. The probands of 3 families and 4 sporadic patients were diagnosed with HHD based on typical clinical and histologic evidence by experienced dermatologist. The proband in family 1 (II-1) was a 41-year-old woman who had a 15-year history of papulovesicular lesions, scaly erythematous plaques, vesicles, erosions and scab, involving axillae, groin, labia majora, and popliteal fossa (Fig. 1a). She complained of itching and pain when the lesions were aggravated by sweating or hot weather. Her mother (I-1) had similarly mild lesions in her neck, armpits, groin, and midriff area. Her sister developed papules in her armpits only when it was hot in summer. The other members in family 1 were asymptomatic individuals. The proband in family 2 (II-2) was a 47-year-old woman with a history of recurrent pruritic erythema and painful erosions in her neck, bilateral axillary, and inguinal areas since the age of 37 years (Fig. 1b). Her mother also devel-

Two Novel Variants and One Recurrent

Variant in Hailey-Hailey Disease oped similar lesions involving intertriginous areas since the age of 35 years. Other members in family 2 had no clinical manifestations of HHD. The proband of another pedigree and 4 sporadic cases also showed typical HHD skin lesions involving the friction or intertriginous regions of body (Fig. 1c-g).

\section{Mutation Screening}

Genomic DNA was extracted from peripheral blood using a Flexigene DNA Kit according to the manufacturer's instructions (Qiagen, Düsseldorf, Germany). We designed primers flanking all 28 coding exons and intronexon boundaries of the ATP2C1 gene using Primer3 (http://bioinfo.ut.ee/primer3--0.4.0/). All 28 exons of the $A T P 2 C 1$ gene and their flanking intron sequences were amplified by PCR. Primer sequences and PCR conditions are available upon request. The PCR products were purified using SAP (Promega, Madison, WI, USA) and Exo I (Epicentre, Madison, WI, USA). The purified PCR products were sequenced using dye terminator chemistry BigDye3.1 (Applied Biosystems, Foster City, CA,USA). Sequencing reactions were run on $3730 \mathrm{xl}$ genetic analyzer (Applied Biosystems). Sequence comparisons and analysis were performed using PolyPhred Analysis Software [Bhangale et al., 2006].

\section{Results and Discussion}

We detected 3 heterozygous mutations in ATP2C1 in these pedigrees and sporadic cases with HHD (Table 1), including 2 novel mutations (c1673_1674insGTTG, c. $2225 \mathrm{~A}>\mathrm{G}$ ) from 2 sporadic cases. Furthermore, for all 3 pedigrees, we detected 1 previously reported nonsense mutation (c.1402C $>\mathrm{T}$ ). No mutations were found in the other 2 sporadic cases.

The novel mutation c.1673_1674insGTTG in exon 18 found in the sporadic case 1 (Fig. 2a) was an insertion mutation that changed the amino acid at position 560 from isoleucine to threonine and created a premature termination codon 63 codons downstream of the insertion site (p.Ile560ThrfsX63). The other unreported mutation c. $2225 \mathrm{~A}>\mathrm{G}$ in exon 23 with $\mathrm{A}$ to $\mathrm{G}$ substitution at nucleotide 2,225 leading to aspartic acid at codon 742 substituted by glycine (p.Asp742Gly) was found in the sporadic case 2 (Fig. 2b). Using the tool of MutationTaster2 [Schwarz et al., 2014], this variant was predicted to disrupt the splice acceptor site and affected protein features of $A T P 2 C 1$. In 3 pedigrees, a previously known nonsense mutation, c. $1402 \mathrm{C}>\mathrm{T}$ in exon 16 of $A T P 2 C 1$, was identi- 


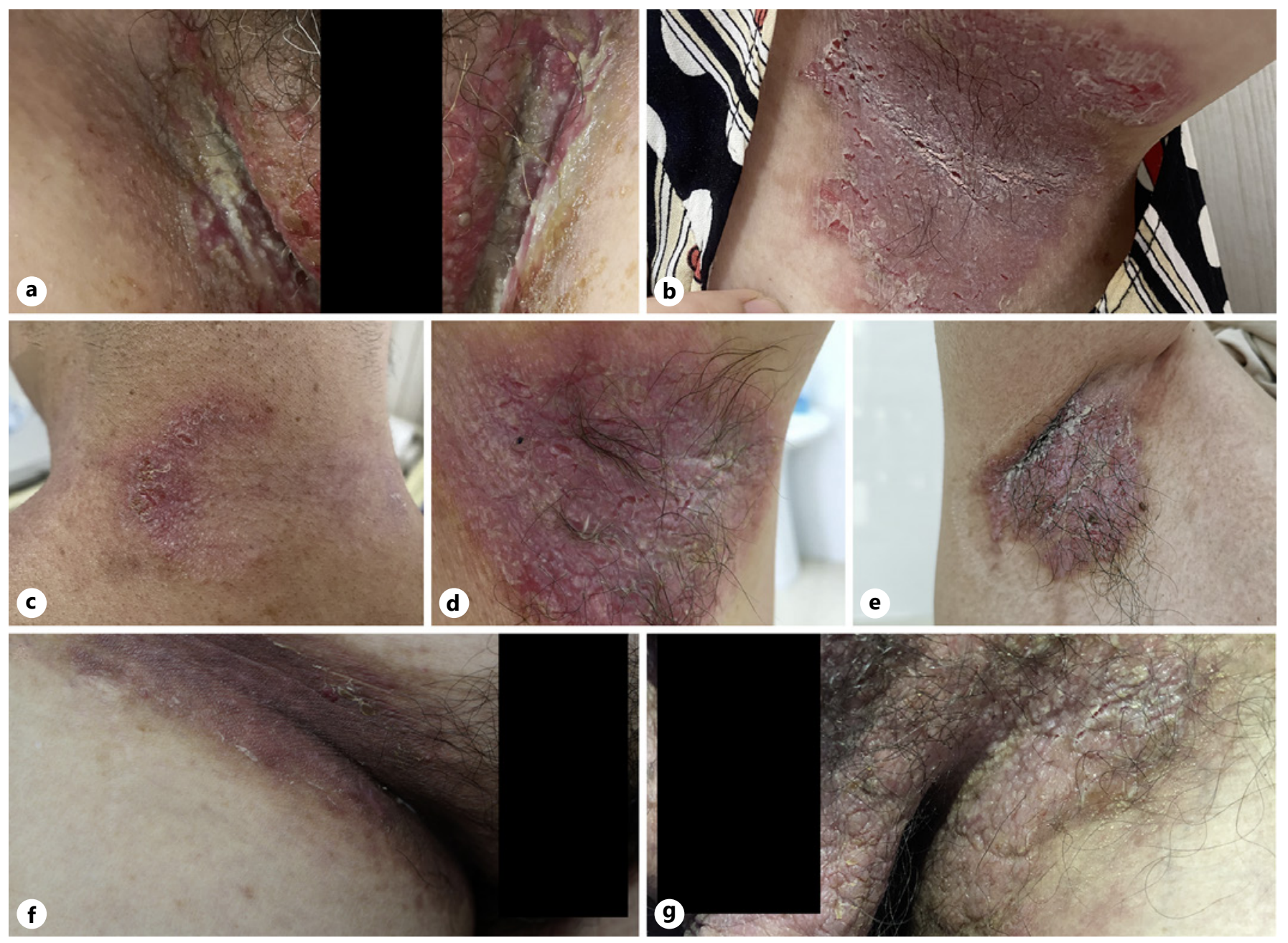

Fig. 1. Clinical manifestations of the proband of 3 pedigrees and 4 sporadic cases. a-c Clinical manifestations of the proband of families 1-3. $\mathbf{d}-\mathbf{g}$ Clinical manifestations of sporadic cases 1-4.

Table 1. ATP2C1 mutations identified in this study

\begin{tabular}{|c|c|c|c|c|c|c|c|c|c|}
\hline \multirow{2}{*}{$\begin{array}{l}\text { Family/ } \\
\text { sporadic case }\end{array}$} & \multicolumn{6}{|l|}{ Mutation } & \multirow{2}{*}{$\begin{array}{l}\text { Affected } \\
\text { individual }\end{array}$} & \multirow{2}{*}{$\begin{array}{l}\text { Asymptomatic } \\
\text { individual }\end{array}$} & \multirow{2}{*}{$\begin{array}{l}\text { Proportion of } \\
\text { mutation detected } \\
\text { in asymptomatic } \\
\text { individual }\end{array}$} \\
\hline & Location & Nucleotide substitution & Amino acid change & Type & $\begin{array}{l}\text { Putative protein } \\
\text { domain }\end{array}$ & Remarks & & & \\
\hline Family 1 & Exon 16 & c. $1402 \mathrm{C}>\mathrm{T}$ & p.Arg468X & Nonsense & P-domain & Recurrent & 3 & 9 & $2 / 9$ \\
\hline Family 2 & Exon 16 & c. $1402 \mathrm{C}>\mathrm{T}$ & p.Arg468X & Nonsense & P-domain & Recurrent & 2 & 3 & $1 / 3$ \\
\hline Family 3 & Exon 16 & c. $1402 \mathrm{C}>\mathrm{T}$ & p.Arg $468 \mathrm{X}$ & Nonsense & P-domain & Recurrent & 3 & 5 & $1 / 5$ \\
\hline Sporadic case 1 & Exon 18 & c.1673_1674insGTTG & p.Ile560ThrfsX63 & Frame-shift & N-domain & Novel & Not applicable & & \\
\hline Sporadic case 2 & Exon 23 & c. $2225 \bar{A}>G$ & p.Asp742Gly & Missense & M6 & Novel & Not applicable & & \\
\hline Sporadic case 3 & \multicolumn{6}{|c|}{ No mutation detection } & Not applicable & & \\
\hline Sporadic case 4 & \multicolumn{6}{|c|}{ No mutation detection } & Not applicable & & \\
\hline
\end{tabular}




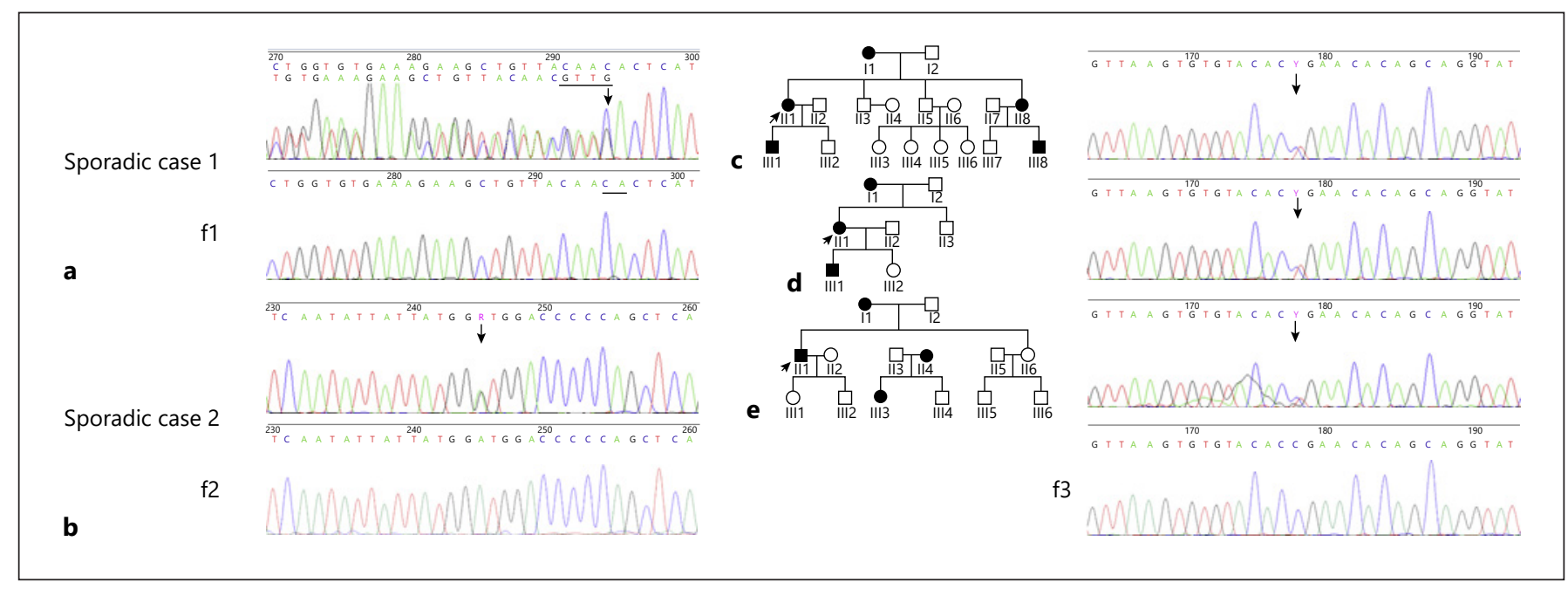

Fig. 2. Genetic findings and pedigree chart of HHD in this study. a Insertion mutation c1673_1674insGTTG (arrow) in exon 18 of $A T P 2 C 1$ in sporadic case 1 . b Substitution mutation c.2225A $>\mathrm{G}$ (arrow) in exon 23 of $A T P 2 C 1$ in sporadic case 2. c-e Pedigree chart of the families1-3 (filled symbols represent affected members; the arrow indicates the proband) and the same nonsense mutation c.1402C $>\mathrm{T}$ (arrow) in exon 16 of ATP2C1. f1-f3 represent sequences of the normal persons, respectively.

fied in probands and affected family members (Fig. 2c-e). This mutation has been previously reported in different families worldwide [Hu et al., 2000; Kellermayer et al., 2006; Cheng et al., 2010; Wang et al., 2019]. This transition resulted in a nonsense mutation of arginine codon (CGA) to a stop codon (TGA) at amino acid residue 468 in the hSPCA1 and premature translation termination (p.Arg468X). The 3 families were native of a limited area in the north of the Jiangxi Province of China, without any known relationship in recent generations. Considering the rarity of HHD and the restricted geographical area of origin shared by the 3 families, we think there may be a founder effect in this region. However, further studies are necessary to confirm this issue. In this study, we also provided the molecular diagnosis for the asymptomatic individuals (Family1-II-3, III-1, III-2, III-3, III-4, III-5, III-6, III-7, III-8; Family2-II-3, III-1, III-2; Family3-II-6, III-1, III-2, III-3, III-4) without clinical manifestations so far. We identified the same mutation c.1402C $>\mathrm{T}$ in the asymptomatic individuals (Family1-III1, III8; Family2III1; Family3-III3) and excluded the possibility of disease in others. Furthermore, none of novel mutations were found in the 100 healthy controls or found in the 3 public variation databases (1000 Genomes Project, HapMap, and Exome Aggregation Consortium), indicating that they are causative mutations rather than a rare polymorphism. However, we failed to detect ATP2C1 mutations in the other 2 sporadic cases. Previous investigations have

Two Novel Variants and One Recurrent Variant in Hailey-Hailey Disease also reported an absence of $A T P 2 C 1$ mutations in some HHD patients. One reason may be that the mutations were in the areas that we did not detect, such as introns, exons of noncoding regions, or promotor regions. In addition, it may be that large deletions or microduplication in ATP2C1 could not be detected by the PCR-based detection method usually used [Yokota et al., 2002; Teye et al., 2020]. And whole-exome sequencing should be considered to determine whether there is another unknown gene related to HHD.

$\mathrm{HHD}$ is an inherited blistering dermatosis characterized by recurrent erosions and erythematous plaques at sites of friction. Since a mutation in the ATP2C1 gene was first reported in patients with HHD in 2000, at least 214 ATP2C1 gene mutations have been discovered up to now (Human Gene Mutation Database, HGMD, http://www.hgmd.cf. ac.uk/ac/index.php). These mutationsare scattered throughout the ATP2C1 gene with no hotspots [Wang et al., 2019]. hSPCA1, which is encoded by the ATP2C1 gene, consists of an actuator domain $(A)$, nucleotide-binding domain $(\mathrm{N})$, phosphorylation domains (P), 5 stalk helices, and 10 transmembrane helices (M1-M10) [Micaroni et al., 2016]. In this study, the novel mutation c1673_1674insGTTG was in the $\mathrm{N}$ domain of hSPCA1. Mutations in this region may influence the nucleotide binding of $A T P 2 C 1$, thus causing the dysfunction of the protein. The novel mutation c.2225A $>\mathrm{G}$ was located in or close to the predicted ion-binding site created by amino acids in M6 according to the predicted struc- 
ture of human hSPCA1 [Muncanovic et al., 2019]. The conserved residues in this region were regarded as the $\mathrm{Ca}^{2+}$ and $\mathrm{Mn}^{2+}$ binding associated functional sites [Wei et al., 2000; Wang et al., 2019]. The nonsense mutation c.1402C $>\mathrm{T}$ located in the P domain of hSPCA1 was predicted to disrupt catalytic phosphorylation [Ton and Rao, 2004]. At present, HHD is considered to be caused by haploinsufficiency of ATP2C1 mutants rather than dominant-negative effects, and more than $50 \%$ of all ATP2C1 mutations may generate premature termination codons, leading to the synthesis of a truncated form of hSPCA1 [Deng and Xiao, 2017]. Undoubtedly, the novel frameshift mutation c1673_1674insGTTG and recurrent nonsense mutation c. $1402 \mathrm{C}>\mathrm{T}$ in our study could lead to premature termination during gene transcription, which predicts the marked reduction of mutated hSPCA1 polypeptide via nonsensemediated mRNA decay [Ma et al., 2008]. The specific mechanism by which mutations in the ATP2C1 gene results in epidermal defects is not quite clear yet. One possibility is that a decrease in $\mathrm{Ca}^{2+}$ concentration in the Golgi caused by haploinsufficiency of ATP2C1 could alter the sorting of desmosomal proteins or their glycosylation [Jia et al., 2019]. This may result in the inability to maintain structurally intact desmosomes, leading to the acantholysis characteristic of HHD [Dobson-Stone et al., 2002]. The identification of ATP2C1 gene mutation is of great significance because patients with HHD may get genetic counseling and prenatal diagnosis. Unfortunately, in our study, the 3 family members with the same mutation had different clinical manifestations, including the age of onset, organ manifestations, course of disease, and disease severity; this is consistent with the results of previous studies, indicating that there is no significant correlation between genotype and phenotypic features in HHD; renders it impossible to predict the phenotypic features in the offspring of HHD patients. The extensive phenotypic variation suggests the influence of other yet unknown modifying genes. Additionally, the skin lesions may be influ- enced by extrinsic factors, such as heat, sweating, mechanical trauma, infection, and exposure to ultraviolet $\mathrm{B}$ radiation. Accumulation of gene mutations and clinical reports will facilitate further elucidation of disease pathogenesis.

In conclusion, we identified 2 novel mutations and 1 previously reported nonsense mutation in Chinese HHD patients. Our results would further expand the mutation spectrum of the ATP2C1 gene and help extend our knowledge of HHD.

\section{Statement of Ethics}

The study was approved by the Second Affiliated Hospital of Nanchang University Ethics Committee and was performed according to the principles of the Declaration of Helsinki. Written informed consent was obtained from all participants.

\section{Conflict of Interest Statement}

The authors have no conflicts of interest to declare.

\section{Funding Sources}

This work was supported by grants from the National Natural Science Foundation of China (No.81960569) and the Natural Science Foundation of Jiangxi Province (No. 20202BAB206034).

\section{Author Contributions}

Zhen Xiao and Chun-Ming Li designed and coordinated the study. Zhi-Gang Liu and Jian-rong Zeng collected the clinical data and assessed the pathological features of the case. Xiao-Liang Ou Yang and Si-Min Yu performed molecular genetic studies and analyzed the data. Zhen Xiao wrote the manuscript, and Chun-Ming Li revised the manuscript. All authors read and approved the final manuscript.

\section{References}

Bhangale TR, Stephens M, Nickerson DA. Automating resequencing-based detection of insertion-deletion polymorphisms. Nat Genet. 2006;38(12):1457-62.

Bitar A, Giroux JM. Treatment of benign familial pemphigus (Hailey-Hailey) by skin grafting. Br J Dermatol. 1970;83(3):402-4.

Burge SM. Hailey-Hailey disease: the clinical features, response to treatment and prognosis. $\mathrm{Br}$ J Dermatol. 1992;126(3):275-82.

Cheng TS, Ho KM, Lam CW. Heterogeneous mutations of the ATP2C1 gene causing HaileyHailey disease in Hong Kong Chinese. J Eur Acad Dermatol Venereol. 2010;24(10):12026.
Cockayne SE, Rassl DM, Thomas SE. Squamous cell carcinoma arising in Hailey-Hailey disease of the vulva. Br J Dermatol. 2000;142(3):540-2.

Deng $\mathrm{H}$, Xiao $\mathrm{H}$. The role of the ATP2C1 gene in Hailey-Hailey disease. Cell Mol Life Sci. 2017; 74:3687-96.

Dobson-Stone C, Fairclough R, Dunne E, Brown J, Dissanayake M, Munro CS, et al. HaileyHailey disease: molecular and clinical characterization of novel mutations in the ATP2C1 gene. J Invest Dermatol. 2002;118(2):338-43.

Engin B, Kutlubay Z, Çelik U, Serdaroğlu S, Tüzün Y. Hailey-Hailey disease: a fold (intertriginous) dermatosis. Clin Dermatol. 2015; 33:452-5. 
Furue M, Seki Y, Oohara K, Ishibashi Y. Basal cell epithelioma arising in a patient with HaileyHailey's disease. Int J Dermatol. 1987;26(7): 461-2.

Hailey H, Hailey H. Familial benign chronic pemphigus. Report of 13 cases in 4 generations of a family and report of 9 additional cases in 4 generations of a family. Arch Dermatol Syphilol. 1939;39:679-85.

Holst VA, Fair KP, Wilson BB, Patterson JW. Squamous cell carcinoma arising in HaileyHailey disease. J Am Acad Dermatol. 2000; 43(2 Pt 2):368-71.

Hu Z, Bonifas JM, Beech J, Bench G, Shigihara T, Ogawa $\mathrm{H}$, et al. Mutations in ATP2C1, encoding a calcium pump, cause Hailey-Hailey disease. Nat Genet. 2000;24(1):61-5.

Ikeda S, Welsh EA, Peluso AM, Leyden W, Duvic M, Woodley DT, et al. Localization of the gene whose mutations underlie Hailey-Hailey disease to chromosome 3q. Hum Mol Genet. 1994;3(7):1147-50.

Jia WX, Zhang WL, Zhao SJ, Li WR, Wu YD, Ma $\mathrm{HJ}$, et al. Three novel ATP2C1 mutations in Chinese patients with Hailey-Hailey disease. Postepy Dermatol Alergol. 2019;36(6):76771.

Kellermayer R, Szigeti R, Keeling KM, Bedekovics T, Bedwell DM. Aminoglycosides as potential pharmacogenetic agents in the treatment of Hailey-Hailey disease. J Invest Dermatol. 2006;126(1):229-31.
Kono M, Kodera M, Inasaka Y, Hasegawa I, Muro Y, et al. Hailey-Hailey disease with oesophageal involvement due to a previously unreported ATP2C1 mutation. Eur J Dermatol. 2019. Online ahead of print.

Korner J, Rietschel M, Nothen MM, Wilk CM Bauer R, et al. Familial cosegregation of affective disorder and Hailey-Hailey disease. $\mathrm{Br} \mathrm{J}$ Psychiatry. 1993;163:109-10.

Ma YM, Zhang XJ, Liang YH, Ma L, Sun LD, Zhou FS, et al. Genetic diagnosis in a Chinese Hailey-Hailey disease pedigree with novel ATP2C1 gene mutation. Arch Dermatol Res. 2008;300(4):203-7.

Micaroni M, Giacchetti G, Plebani R, Xiao GG, Federici L. ATP2C1 gene mutations in Hailey-Hailey disease and possible roles of SPCA1 isoforms in membrane trafficking. Cell Death Dis. 2016;7(6):e2259.

Muncanovic D, Justesen MH, Preisler SS, Pedersen PA. Characterization of Hailey-Hailey Disease-mutants in presence and absence of wild type SPCA1 using Saccharomyces cerevisiae as model organism. Sci Rep. 2019;9(1): 12442.

Richard G, Korge BP, Wright AR, Mazzanti C, Harth W, Annicchiarico-Petruzzelli M, et al. Hailey-Hailey disease maps to a $5 \mathrm{cM}$ interval on chromosome 3q21-q24. J Invest Dermatol. 1995;105(3):357-60.

Schwarz JM, Cooper DN, Schuelke M, Seelow D. MutationTaster2: mutation prediction for the deep-sequencing age. Nat Methods. 2014; 11(4):361-2.
Teye K, Koga H, Hamada T, Matsuda M, Ichiki M, Numata S, et al. A Novel Microduplication Spanning Exons 8-16 of ATP2C1 That Was Undetectable by Standard Sanger Sequencing in a Japanese Patient With Hailey-Hailey Disease. Front Med. 2020;7:492.

Ton VK, Rao R. Functional expression of heterologous proteins in yeast: insights into $\mathrm{Ca} 2+$ signaling and $\mathrm{Ca} 2+-$ transporting ATPases. Am J Physiol Cell Physiol. 2004;287:C580-9.

Wang Z, Li L, Sun L, Mi Z, Fu F, Yu G, et al. Review of 52 cases with Hailey-Hailey disease identified 25 novel mutations in Chinese Han population. J Dermatol. 2019;46(11):1024-6.

Wei Y, Chen J, Rosas G, Tompkins DA, Holt PA, Rao R. Phenotypic screening of mutations in Pmr1, the yeast secretory pathway $\mathrm{Ca} 2+1$ $\mathrm{Mn} 2+-\mathrm{ATPase}$, reveals residues critical for ion selectivity and transport. J Biol Chem. 2000;275(31):23927-32.

Wilgram GF, Caulfield JB, Lever WF. An electron-microscopic study of acantholysis and dyskeratosis in Hailey's disease. J Invest Dermatol. 1962;39:373-81.

Xiao H, Huang X, Xu H, Chen X, Xiong W, Yang $Z$, et al. A novel splice-site mutation in the ATP2C1 gene of a Chinese family with Hailey-Hailey disease. J Cell Biochem. 2019; 120(3):3630-6.

Yokota K, Yasukawa K, Shimizu H. Analysis of ATP2 $\mathrm{C} 1$ gene mutation in 10 unrelated Japanese families with Hailey-Hailey disease. J Invest Dermatol. 2002;118(3):550-1. 